\title{
Essay
}

\section{Organic First: A Biology-friendly Chemistry Curriculum}

\section{David Reingold}

\author{
Department of Chemistry, Juniata College, Huntingdon, PA 16652
}

Received January 5, 2005; Revised January 13, 2005; Accepted May 23, 2005

Monitoring Editor: Elizabeth Vallen

In a previous essay, I have described Juniata's unusual organic-first curriculum (Reingold, 2001) (http://faculty. juniata.edu/reingold/phil.doc). The current essay describes to biologists the advantages of this approach, on the assumption that few biologists are regular readers of Journal of Chemistry Education and therefore are probably unaware of our method for integrating chemistry and biology curricula.

I begin with the assumption that the majority of students taking college chemistry are biologists or pre-health-professions students. It is a rare lower-level chemistry course that has more than $20 \%$ of its enrollment composed of potential chemistry majors. Thus, first- and second-year chemistry courses are composed of somewhere between $50 \%$ and $95 \%$ biology-oriented students, depending of the strength of chemical engineering at the institution. However, I follow this assumption with a conclusion that is startling in its simplicity: if most of the students in our courses are biologists, we should structure the curriculum so that it is most useful to them.

Imagine a chemistry department unencumbered with the history of how chemistry has been taught for years, and also unrestricted by the expertise of its faculty to require a certain sequence of courses in order to keep them occupied. Imagine also that this department set out to design a curriculum from scratch with the express purpose of making the chemistry offerings at the lower level of maximum benefit to its main customers, the biology students. What do you suppose they would come up with? I submit to you that these chemists would not design a course in "General Chemistry," highly physical in its approach and highly varied in its content. In most general chemistry courses, the (apparently unrelated) topics abruptly change from week to week, and much of the material is presented as an introduction to topics the students might see two years later, if at all. Furthermore, many students interested in both chemistry and biology have the former interest beaten out of them because the chemistry content has little if any relevance to their combined interests. I have explained many additional problems with general chemistry (Reingold, 2001) and have summarized these in Table 1. Yet general chemistry is the course that most chemistry departments teach to first-year students, the

DOI: $10.1187 /$ cbe.05-01-0063

Address correspondence to: I. David Reingold (reingold@ juniata.edu). majority of whom are taking chemistry because they want to major in biology. Why do we do this? Probably because this is the way chemistry has always been taught.

Having established what we should not teach to first-year biology students, it remains to be determined what we should teach. I would argue that with the increasing emphasis in biology on understanding phenomena at the cellular and molecular level, the most useful outcome a chemistry department can provide for its biology students is a thorough understanding of organic chemistry. The sooner we introduce the probable biology majors to organic chemistry, the better it will be for those students. Biology departments could build on the students' knowledge of organic chemistry without waiting until the end of the sophomore year. How soon can students begin learning organic chemistry? The answer is, right away.

How is this possible? Most chemistry departments require a year of general chemistry as a prerequisite for organic chemistry. Traditionally, the only students who are allowed to begin organic immediately are those who had a strong high school background and can skip general chemistry. How can I claim that first-term students can begin organic chemistry immediately? Because Juniata and a few other schools have been doing it for years, and it works (Coppola et al., 1997; Ege et al., 1997).

Ask your organic chemists, how much of general chemistry is really necessary for students taking organic chemistry? The answer is, not much. The important parts of general chemistry are reviewed in the first chapter of every organic book, and it does not cover much. Lewis structures, bonding, polarity, hybridization (which the students swear they have never seen before and which is always taught in the organic course as if it were brand new), acids and bases, some kinetics, and thermodynamics. That's about the sum total of general chemistry necessary to learn organic. This amount of material could be covered in about five weeks; the rest of general chemistry is useless as far as learning organic is concerned. I suggest, therefore, that our imaginary chemistry department would invent a course that begins with about five weeks of preliminary material and then dives directly into organic chemistry.

You probably noticed an immediate problem with this proposal. Organic chemistry is a two-semester course at every university. If we spend five weeks on preliminary 
Table 1. Problems with general chemistry

Familiarity

Survival strategies

Math preparation

Disjointedness

Playing field

Symbolism
It is too much like high school chemistry. They believe it is the same old stuff.

They were taught algorithms to get the right answer even though many have no clue how or why these tricks work.

It is too mathematical.

It is a mish-mash of topics with no obvious connection.

Students have too wide a range of preparation. It is virtually impossible to teach at a level that is simultaneously appropriate for all these students.

It asks students to do calculations on systems they are not equipped to understand. material that usually occupies one week of review, we have lost five weeks of organic content. There is a second problem that you may not have noticed. With relatively few exceptions, most organic courses spend two semesters covering the broad field but run out of time before reaching the four chapters at the end of the book that cover biologically relevant chemistry (i.e., the chemistry of amino acids, proteins, carbohydrates, and nucleic acids). We chemists spend so much time stuffing the students full of organic chemistry that we never cover in detail the biologically relevant material they actually took the course to learn! Most organic texts contain about two to four weeks worth of this material. Obviously, our imaginary chemistry department would make sure to include this in its new firstyear course.

Now our imaginary department has a problem. If it starts with a full-year organic course, adds 5 weeks of preliminary material and 3 weeks of biological material, the new course will no longer fit into a typical academic calendar. Is it possible to save time in other areas of organic chemistry to trim the proposed course by eight weeks? Is there really eight weeks worth of material in a traditional organic course that can be purged? Yes, there is. The key to being able to reduce the scale of organic chemistry is to recognize that your market is the biology students. Organic chemistry that is not useful to biologists does not need to be in this first course. There really is eight weeks of this "excess" material (Table 2). The key to persuading your chemists to delete this material is to point out that their students are not losing it. Only the biology students lose it, and I assure you they will not complain! The chemistry students, who do need this material, can get it in a follow-up organic course for junior chemistry majors. Indeed, the prospect of teaching organic a second time through, to a small class of just chemistry students, will be highly attractive to your organic chemists.

Obviously, our imaginary department actually exists here at Juniata College. We have created a first-year course based on biologically relevant organic chemistry. It includes the necessary introductory material and the often-omitted biological material, and it omits much of the esoteric organic chemistry that is of interest only to chemists. As other schools consider implementing such a curriculum, an important question is, "What text will we use?" Standard organic texts have too little introduction and too much organic, as mentioned above. The next level of text is a "General, Organic, and Biochemistry" text that is usually intended as a one-semester overview of chemistry for students (such as nurses) who need only one semester. Such books tend to be too basic to serve as the basis of two years of chemistry, often leaving out mechanisms, energy, and synthesis at any level of sophistication. In an effort to fill that gap, I authored a text specifically for the type of course I describe in this essay (Reingold, 2002).

In addition to the advantages of connecting biology and chemistry at the earliest possible level, the organic-first approach has additional advantages. Many students who manage to get through the first year of chemistry and biology are overwhelmed by organic chemistry when they take it. Indeed, organic chemistry is known worldwide as a great weed-out course. Although there are few teachers who set out to fail students, it is undeniable that organic chemistry deters many students from certain careers. It would be beneficial for these unfortunate students to find out sooner than their sophomore year that their chosen career path is not to be, forcing them to start all over in some other field. Teaching organic first accelerates this reality check by a year and expedites students' decisions that are more appropriately matched with their aptitudes.

Of course, teaching organic first throws off the rest of the chemistry curriculum. What does one teach sophomore year? At Juniata, our sophomore courses cover much of the material that used to be covered in general chemistry, but now the content is treated at a higher level of sophistication. Teaching "general chemistry" second has the advantage of postponing the more mathematically rigorous chemistry until the sophomore year, when students can benefit from another year of maturity and (perhaps) some additional math courses. It also represents a steady increase in the mathematical sophistication with which chemical topics are treated, progressing from the qualitative (freshman organic) to the more rigorous (sophomore) to the heavy hitter (physical chemistry).

The current hot topic in biology education is Bio 2010, which advocates putting more math into the early stages of college biology courses. Doesn't this proposal fly in the face of those recommendations? I argue not: current biology courses have too little math, whereas current chemistry courses have too much. By adding math to biology courses and postponing it in chemistry courses, we can spread it more evenly throughout the curriculum and help students see math as integral to science rather than a hindrance to learning it.

An important question to ask is, "How well does this curriculum work?" I can tell you that Juniata students have been getting into graduate and medical schools at the same rate as they always have and continue to do extremely well in those schools. Their success in graduate and professional schools counters the potential criticism that inverting the first 
Table 2. Deleted organic material

Free radical halogenation

Free radical additions

Borane additions

Peroxide workup of ozonolysis

Competition between strong and weak o,p. directors

Diazonium salts

Nucleophilic aromatic substitution

Silyl protecting groups

Industrial polymers

Diels-Alder reaction

Least hindered approach of reagents

Wittig reaction and other ylids

Wolf-Kishner, Clemmenson

Organolithium chemistry

Organocopper chemistry

Diazomethane

Acid-catalyzed condensation reactions

Baeyer-Villiger reaction

Permanganate oxidations

Osmium tetroxide oxidations

Periodate oxidations

Gabriel synthesis

Nitrile chemistry

Carbenes

Pericyclic reactions two years of chemistry is detrimental to their education. Our numbers of majors are as high as they have even been. However, we have relatively little in hard data to answer the question. Assessment has increased in visibility and importance over the past 15 years, and at the time we began our experiment, we did not think carefully enough about about how to evaluate the impact of a curricular change, particularly one that would have its major impact on a discipline other than chemistry. I recommend that any department seriously interested in embarking on such an adventure consult with colleagues skilled in designing assessment tools in order to obtain quantitative data on the impact of the change. This should be part of the planning strategy accompanying the process, and collecting data before the change is implemented would be a critical component in establishing a baseline against which future outcomes could be compared. I would be happy to remind any department willing to undertake a similar innovation in their chemistry program of the mistakes we made.

Finally, biologists convinced of the benefits of this approach might well wonder, how can we persuade our chemistry colleagues to consider this? Of course, if I knew the answer to that I'd be rich. I have been publicizing this approach for some time, and the response from chemists in the audience is almost always that, intellectually, it makes perfect sense, but we will never do it. The reason seems to have a great deal to do with inertia, especially at research universities where the faculty (in general) want to spend as little time as possible preparing for courses and therefore are reluctant to embark on a curriculum that will require every member of the department to change what they do. My best advice is to focus on chemistry departments that are sincerely interested in curriculum revision and are willing to lay everything on the table. Point out that our curriculum has been approved by the Committee on Professional Training of the American Chemical Society. Send them copies of my articles and suggest that they invite me to visit and discuss our curriculum with them. I'll be happy to go anywhere to talk about this.

In summary, teaching organic first has many advantages, especially for students and faculty in biology departments, and few disadvantages. The online discussion forum available with this essay may provide a joint chemistrybiology meetingplace where faculties can exchange ideas and concerns. I hope this essay catalyzes some discussions between chemistry and biology departments and promotes some curricular experiments.

\section{REFERENCES}

Coppola, B.P., Ege, S.N., and Lawton, R.G. (1997). The University of Michigan undergraduate chemistry curriculum 2. Instructional strategies and assessment. J. Chem. Educ. 74, 84-94.

Ege, S.N., Coppola, B.P., and Lawton, R.G. (1997). The University of Michigan undergraduate chemistry curriculum 1. Philosophy, curriculum, and the nature of change. J. Chem. Educ. 74, 74-83.

Reingold, I.D. (2001). Bioorganic first: a new model for the college chemistry curriculum. J. Chem. Educ. 78, 869. http://jchemed.chem. wisc.edu/Journal/Issues/2001/Jul/abs869.html for subscribers.

Reingold, I.D. (2002). Organic Chemistry: An Introduction Emphasizing Biological Connections. Boston: Houghton Mifflin Co. 